The University of Akron

\title{
IdeaExchange@UAkron
}

Proceedings from the Document Academy

University of Akron Press Managed

December 2018

\section{The Wonders of the Augsburg Cabinet: Three Ways of Experiencing a Document}

Kiersten F. Latham

Kent State University, kflatham@kent.edu

Please take a moment to share how this work helps you through this survey. Your feedback will be important as we plan further development of our repository.

Follow this and additional works at: https://ideaexchange.uakron.edu/docam

Part of the Library and Information Science Commons, and the Museum Studies Commons

\section{Recommended Citation}

Latham, Kiersten F. (2018) "The Wonders of the Augsburg Cabinet: Three Ways of Experiencing a Document,"

Proceedings from the Document Academy: Vol. 5 : Iss. 2 , Article 10.

DOI: https://doi.org/10.35492/docam/5/2/10

Available at: https://ideaexchange.uakron.edu/docam/vol5/iss2/10

This Conference Proceeding is brought to you for free and open access by University of Akron Press Managed at IdeaExchange@UAkron, the institutional repository of The University of Akron in Akron, Ohio, USA. It has been accepted for inclusion in Proceedings from the Document Academy by an authorized administrator of

IdeaExchange@UAkron.For more information, please contact mjon@uakron.edu, uapress@uakron.edu. 


\section{Introduction}

This project started with an unexplainable sense of connection between myself and a 16th century cabinet of curiosity. Since even before Frohmann (2009) proposed his document analysis on the meaning of cabinets of curiosity, I have been fascinated with them. Their emergence in the 15th century (MacGregor, 2007) is also the tantalizing beginning of the birth of the modern museum. In museum studies, we often ask what the meaning and purpose of the museum is today (Latham \& Simmons, 2014); I believe that part of the answer to this question is in these curious compartmentalized pieces of furniture that held the wonders of the world and helped their users make meaning a very long time ago. My encounter in 2016 with one of these wonders, the Augsburg Cabinet in Uppsala, Sweden, stimulated an even stronger desire to delve into the intense fascination I have with cabinets of curiosity.

Taking heed of Kari's (2007) declaration that there is a need in information science for more of people's in-the-moment engagement with information, along with a recent paper I co-wrote (Gorichanaz, Latham, \& Wood 2018) about the lifeworld as a unit of analysis, I wanted to investigate lived experience with a document. During a recent collaborative study, co-conducted with colleagues (Latham, Gorichanaz, \& Narayan, 2018), we used auto-hermeneutics to explore our inspirational encounters in museums. After successfully conducting the study, I decided to use this data collection methodology in the current study to capture my in-the-moment experiences with the Augsburg cabinet-in three different modes of experience. Auto-hermeneutics is "a systematic way to explore and describe the ontological nature of one's own lived experiences" (Gorichanaz, 2017, p. 3), a study of the self and a unique approach to building an understanding of phenomena of interest to information science. It reaches squarely into those in-the-moment experiences of which Kari spoke.

At the same time, I wanted to take my research (Latham, 2015) on "the real thing" (TRT) in museums to another level. In that study, I found that adult visitors to museums perceived "real" in this context in multiple ways and that there is more than one way to understand what is perceived as real in the museum. In my study, I found that people experienced "the real thing" in four ways, through themselves (Self), through others (Relation), through the physical thing itself (Presence), and through the context (Surround). Continuing on the path of work I have done on information experience, I took this opportunity to apply a new methodology (autohermeneutics) to an area I have previously researched (the notion of "the real thing" in museums) and to explore a type of document that intrigues me (a cabinet of curiosity). 
This paper presents that exploration. It is part story and part systematic study. Indeed, it is also partial, in that this paper is a first step in a longer process of studying such situations using this methodology. For this study, I was interested in digging more deeply into my own lived experience of the cabinet and to explore an in-the-moment approach to data collection. I was also interested in applying my past research results on people's perceptions of "the real thing" in museums to this particular thing. In that sense, this is a two-part study: one "tried on the TRT results for size," so to speak, and the other explored what it was like to experience the cabinet three different modes.

The study involved systematic data collection (recordings and writings) of my own experiences with the Augsburg Cabinet in three modes: a live gallery visit, a tour led by a docent, and a digital tour/interactive. This was followed by an exploratory qualitative approach to analysis guided by van Manen's $(2011,2014)$ phenomenological (reflective) thematic analysis, which involves the process of recovering structures of meanings embodied in human experience represented in a text. This involved the production of textual "portrayals" (van Manen, 2014). For van Manen, all phenomenological inquiry results in rich, reflective writing that resonates and make intelligible the kinds of meanings made in life as we live it (2011). The story aspect is here in this paper, in the rich narrative description. In fact, this story-telling aspect of the encounter is a form of analysis itself (van Manen, 2014). As reflective phenomenological writing "the researcher not only engages in analysis but also aims to express the noncognitive, ineffable, and pathic aspects of meaning that belong to the phenomenon" (p. 240). In the analysis, I also used Interpretative Phenomenological Analysis (IPA) (Smith, Flowers, \& Larkin, 2007) to conduct a second thematic analysis that gave me a bit more structure. The analysis portion of this study then, uses phenomenological methods and methodologies.

In this paper, I begin by introducing the Uppsala Augsburg Cabinet, telling the story of our first meeting. Following this, I outline the methodology used, providing detail in both data collection and analysis because the exploration of method was one of the main goals of this project. I describe my encounter with each mode in rich descriptive writing, following van Manen (2014) who says phenomenological inquiry is practiced as phenomenological writing which is the very act of making contact with the things of the world. This is followed by a discussion of the thematic outcomes of Interpretative Phenomenological Analysis of the transcript data. I also conducted a short analysis in which I used The Real Thing research results to analyze my experiences of the document in each of the three modes. Finally, I reflect on what I learned through this exploration and ponder what it means for the future. 


\section{The Augsburg Cabinet History and the Story of our First Meeting}

One can see examples of these types of Renaissance cabinets (freestanding furniture) scattered across the world and in various kinds of museums, but today there are very few in existence that also hold their original contents-those collected wonders chosen by the cabinets' owners and/or creators. The Augsburg Cabinet in the Gustavianum, Uppsala, Sweden is one of those rarities. Finished in 1632, the cabinet itself exists, in all its glory, and so do about 1000 pieces that were contained in its original collection (Josefsson, 2014). The Swedish King Gustav II Adolf received the Cabinet as a gift from the city governors of Augsburg in 1632, during the Thirty Years war, but died before it arrived in Uppsala a year later. It has been in Uppsala ever since, either in a royal residence or at the University. The Cabinet now sits in the University of Uppsala's museum, named after the King the Cabinet was originally bequeathed to, the Gustavianum.

When I first saw this cabinet, in 2016, I had no idea what I was witnessing as I had not realized it was here, in this unassuming university museum. Its presence was not advertised widely and it was not a focal point in the advertisement of the museum. In fact, I had come to the Gustavianum to see the anatomical theatre, which was built in 1663 by medical professor Olaus Rudbeck (Uppsala Universitet, n.d.). Seeing the cabinet, in its current configuration on exhibit, was an encounter filled with profound excitement and joy. I was surprised and in awe and couldn't take enough photographs to capture my excitement over the meeting. I remember smiling a lot and having a feeling of comfort around it. I bought every book about it in the gift shop and vowed to come back in the future. Since my encounter in 2016, I have been keen on working with the cabinet, but as I am not a historian, art historian, nor anything related to those professions, I was unsure how to proceed. I am a documentologist and my interest is in this cabinet as a document. In particular, I am focused on lived experiences around the cabinet and its contents. Since it is nearly impossible today to gather the lived encounters of those who witnessed it in the 17th century, I decided to analyze the cabinet in its present position today, as a museum document, using my own lived experiences as data to learn more about document experience and to explore an automethodology that might get closer to lived experiences in the moment they occur.

\section{Methodology}

My goals for this project were threefold: 1) to explore a new approach to "the real thing" (TRT) research (Latham, 2015), 2) to learn something about experiencing a single document in different contexts, and 3) to try a new methodological approach 
on an ongoing inquiry. Taking an auto-hermeneutic approach (Gorichanaz, 2017) to data collection, on March 4, 2018 I visited the cabinet for the second time in less than two years. This time, I planned out the auto-hermeneutic study before my visit. For this study, my research questions were:

RQ1: Is there a qualitative difference in the experience of the same object from three different formats (in person, on tour, digitally)? In other wordsWhat is it like to experience the Augsburg Cabinet in a museum gallery? What is it like to experience The Cabinet on a docent-led tour? What is it like to experience The Cabinet through a digital tour?

RQ2: How does the TRT framework help with understanding those differences?

On this single day, I visited the Cabinet in three different ways. First, a simple gallery visit, one-on-one with the Cabinet, in its presented space and its simple interpretation (text panels, cases, objects). I then went on a docent-led tour in the gallery, in which the cabinet was highlighted, but not the main focus. Finally, I sat down (in the same gallery, but mostly out of sight of the cabinet) and used the digital "tour," a computer interactive in which one is told one can explore the Cabinet in depth. I took handwritten notes and audio-memoed my reactions during these encounters, with the exception of the tour which did not allow for, nor elicit, live memoing. My recorded memos were simply recordings of everything I was thinking, feeling, and wondering in each situation, as it unfolded.

After transcribing all my notes and recordings, I conducted several detailed readings of the transcripts, identifying the thematic expressions, phrases, or longer narratives that let the phenomenological meaning of the experience be revealed, first concretely, then conceptually, then thematically. This thematic work is embedded below in the next step of the analysis, phenomenological writing.

For further guidance in the analysis, I looked to the phenomenological methodologies of Max van Manen (1990, 2011, 2014) for an approach to rich phenomenological expression. For van Manen (2011), there are two methodological "parts" to (hermeneutic) phenomenological inquiry and writing: the reductio (the reduction) and the vocatio (the vocative dimension). The reduction is meant to bring the aspects of meaning that belong to the phenomena of our lifeworld into nearness; reduction refers to a certain attentiveness (2011). Van Manen says phenomenological inquiry is practiced as phenomenological writing which allows us to make contact with the things of our world; this is the vocative dimension. Phenomenological inquiry-writing is based on the idea that no 
text is ever perfect, no interpretation is ever complete, no explication of meaning is ever final, no insight is beyond challenge. Using this approach below, I describe my encounter with each mode in rich descriptive writing (van Manen, 2014) prior to a brief discussion of the thematic emergences of each encounter. To put it another way, first I write the condensed experience story, then discuss the thematic emergences. Below is the order in which I experienced the Cabinet on that day of data collection.

\section{In the Gallery}

I went to the gallery first. My anticipation was intense and very physical. I could feel my heart beating faster as I worked my way to the 1st floor (second American floor) gallery where I knew the cabinet lived, my excitement climbing as I climbed the stairs. In fact, I had to stop before I went into the gallery, to collect my experiences on paper; they were rushing in so fast. My original intention was to record my experiences by handwritten notes. I learned very quickly that I needed to shift to voice-memoing. After stopping in the stairwell to write, I prepared my phone to begin voice recording once I was in the gallery. My original plan included writing down the bits and pieces of my experience-moments - that came to the surface. But those "moments" turned into a constant, in-the-moment record of everything I was thinking and feeling as I witnessed this cabinet. As soon as I walked through the threshold, I couldn't stop memoing (see Figure 1). The Cabinet took my breath away (again).

Figure 1. What you see as you enter the gallery. The cabinet is in the very center, flanked by two globes (not a part of the cabinet, but lovely nonetheless) and museum cases full of the original contents of the cabinet.

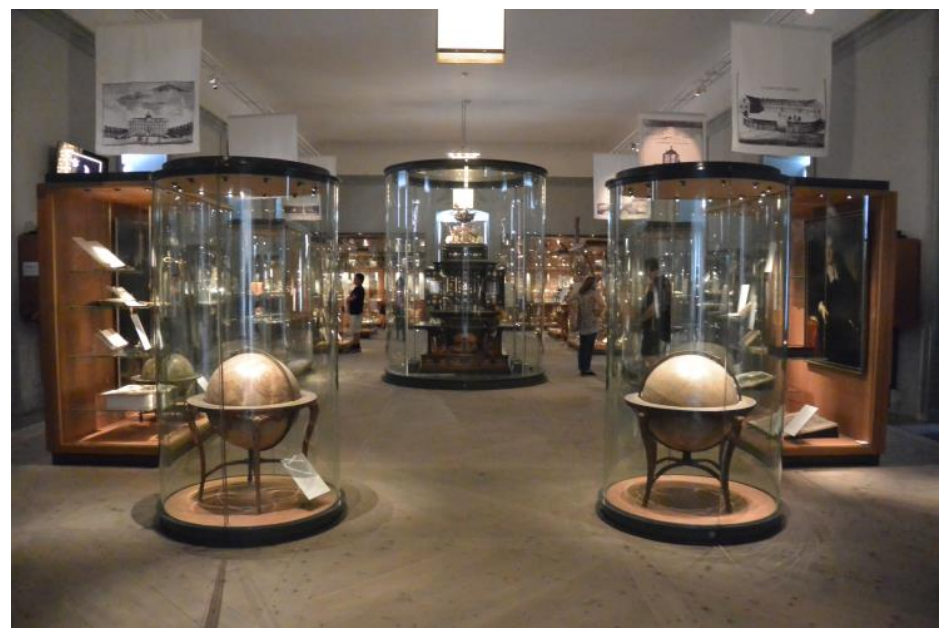


Figure 2. The cabinet itself. You can walk completely around it, looking at all four sides.

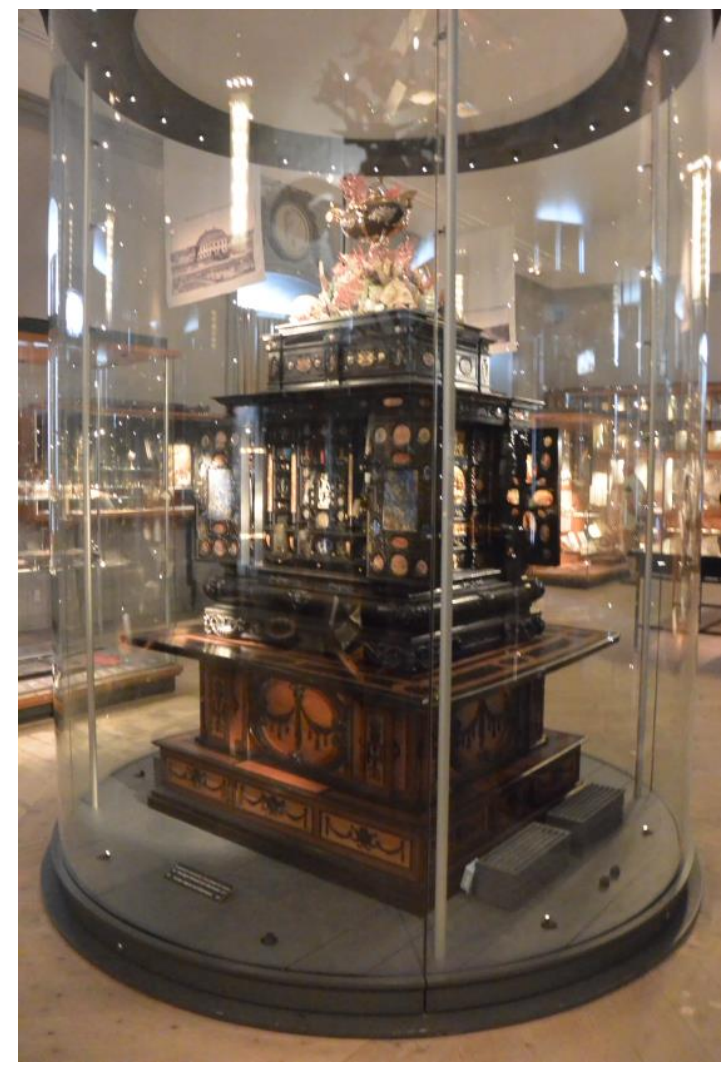

I spent about 32 minutes in the gallery, first spending time with the Cabinet itself and then systematically visiting each of the six cases flanking the Cabinet which held a selection of its original contents. For my focus on the Cabinet itself (see Figure 2), I stopped at each of the four sides of the Cabinet, memoing all my thoughts and feelings. As it was the last time I visited, one side appealed to me more than the others, Side B (see Figure 3; Josefsson, 2014). This side holds a nautilus cup, edged in gold, and was encrusted with insets of many tiny thin slices of stone, so thin that the light shines through from the other side. On these slices were very tiny but extremely detailed paintings, entire scenes, from the Old Testament. Later I discovered that there were even more, different little paintings on the opposite sides of the stone slices. I was in awe. After I felt done with the cabinet, I moved to the three cases on the east side of the gallery showcasing the Cabinet's contents. I looked at things that interested me and it became a bit of a game, trying to figure out what a thing was and navigating to its label, which didn't always give a satisfying answer. Many things were so intriguing, but there was little 
information present that answered my many questions, leading to some frustration. This "game" happened a lot more with the contents cases than with the Cabinet itself. I wanted to know why a lot. Why was this sperm whale tooth chosen (by the Cabinet's creator) and put in this Cabinet? Why would someone want a bottle made of mistletoe? Why would someone even think to make one? And I often wondered about what it would be like to have lived in the 17th century, using this or that object. For example, there are many functional objects present, like a shaving kit and scissors. I tried to imagine waking up in the morning and walking over to my Cabinet, open its door and get out my shaving kit to trim my beard. On occasion during my visit, another visitor would come in the gallery and I found myself getting annoyed that they were interrupting our time together (me and the Cabinet), even though logically I knew this was silly. I discovered that my purposeful looking (and talking to myself about it through the recording process) made me look more closely, and I learned a lot more about the things I saw than the last time I visited. During that first visit, I took it all in as a whole and was overwhelmed by that wholeness. During this second visit, I looked at all the parts and pieces and focused more on each of them. At the end, I felt a bit rushed as the scheduled tour was coming up and I didn't want to miss it. But I would have liked to spend more time in the gallery, alone with the Cabinet.

Figure 3. A detail of Side B of the cabinet, my favorite. The doors are open, and the tiny drawers are visible, giving a glimpse into what people of the past may have also seen. The round medallions are thin pieces of stone upon which are tiny painted scenes.

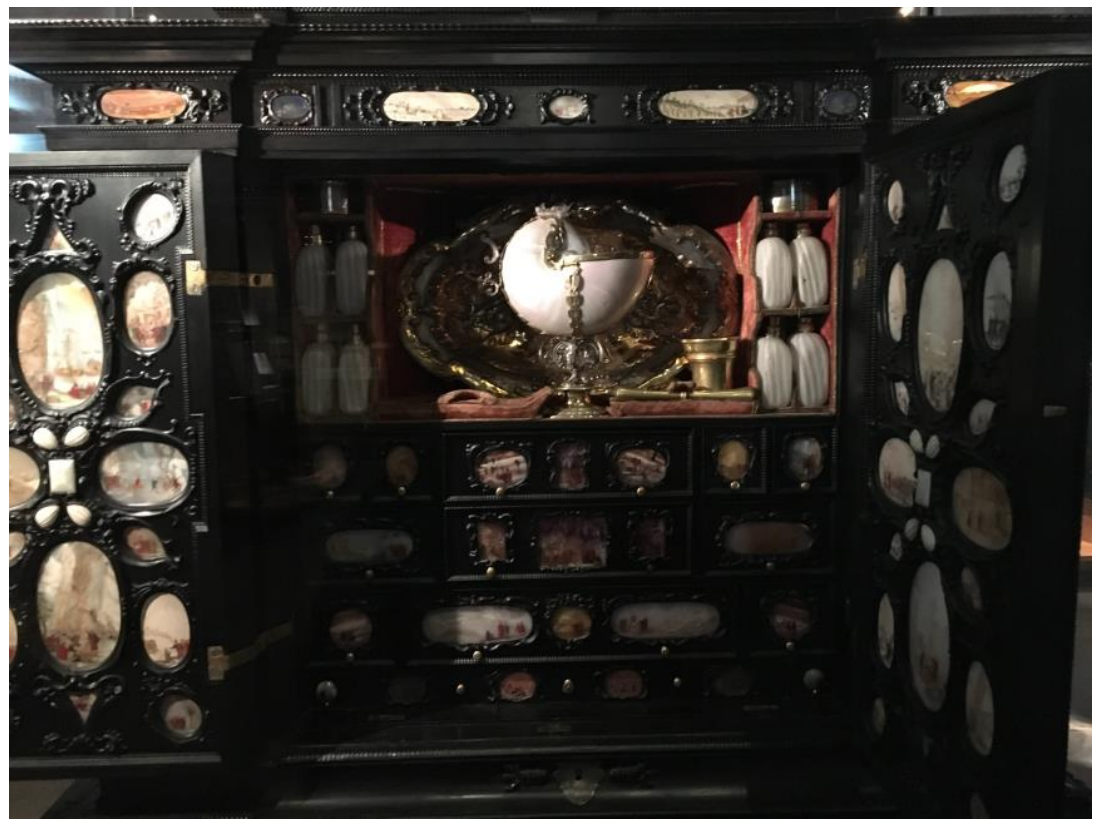


The live gallery visit thematic analysis was the most complex of the three modes of experience. I used various means of bracketing my analysis from the earlier TRT study and I feel confident that I took this case as its own, independently, without trying to map on the TRT study or any other pre-conceived concepts. Five themes emerged from the gallery visit data: Wonder, Appreciating What I See, Personal Meaning, Surrounding Environment has Effect, and Trying To Figure it Out. Wonder refers to experiences of awe, curiosity, and involves asking how, why, who and the story of the object's life and use. It was heavily laden with interest and wanting to know more, as described above. There were also a couple of points where lack of interest was mentioned, and these were considered in this category; sometimes a thing simply did not appeal to me. Appreciating What I See was about recognizing beauty, craftsmanship, and a general appreciation of the work that was witnessed. It also included comments about color, shape, texture and moments about fun and humor. Sometimes awe was blended in with this theme. The theme around Personal Meaning included emotional comments and memory reflections. Surrounding Environment has Effect refers to contextual aspects of the experience, such as the physical surrounding space, the way things were exhibited, the workers behind the exhibition. Context, in this case, provided insight into other inquiries about the Cabinet itself and the stories behind it. This theme also includes reference to feeling more comfortable in the gallery when it was empty of other visitors. Trying To Figure it Out is different from the other four themes. It was about questioning (not wondering), wanting more information, and either the frustration or disappointment when it was not found or the discovery when it finally was. The Trying To Figure it Out theme had the most data, with Wonder following close behind. Appreciating What I See and Personal Meaning came in next, with about half the amount of data representing these themes. Surrounding Environment fell far behind in quantity.

\section{On the Docent-Led Tour}

My second mode of experience with the Cabinet was on a docent-led tour. This was a timed, English language tour given by one of the philosophy students from Uppsala who works at the museum. His delivery was quite good and he told us interesting things. Nevertheless, the docent-led tour yielded the fewest experiential data from me. The tour guide only talked about the cabinet for a short time and he gave only factual information. I was joined in the tour by less than ten fellow participants. With their presence, I did feel the pressure to not voice record into my phone so I took hand-written notes. Even so, I jotted just a few handwritten words. In my notes, I only wrote "factual" bits, like dates and locations and a few 
phrases or definitions (e.g., the Seychelle nut on the top of cabinet was called a "naturalia mountain") and that the west side consisted of depictions of love. The only comment in my notes beyond facts was "interest," i.e., something interested me, everything else was historical facts about the cabinet, dates, number of objects, cost, how many craftsmen worked on it, what the themes are on the sides, etc. I found myself not wondering or imagining as much as I did during the gallery visit. The docent-led tour, while interesting, felt flat and seemed to have less connection to the people and living that emanated from the gallery visit.

\section{Using the Digital Interactive}

The digital "tour" is in the same gallery as the Cabinet and its contents. It is mounted on the back of one of the main display cases (see Figure 5) and feels quite hidden and dark. There is a fairly comfortable bench against the wall, and you can see the actual Cabinet off to the side (see Figure 6) through a break between the cabinet backs. The interactive consists of a screen mounted to the wall (which was the back of the exhibit case) and a roller ball to select options on the screen.

Figure 4. Our docent talking about the cabinet. He spoke for only about 8 minutes about the cabinet, out of a 30-minute tour.

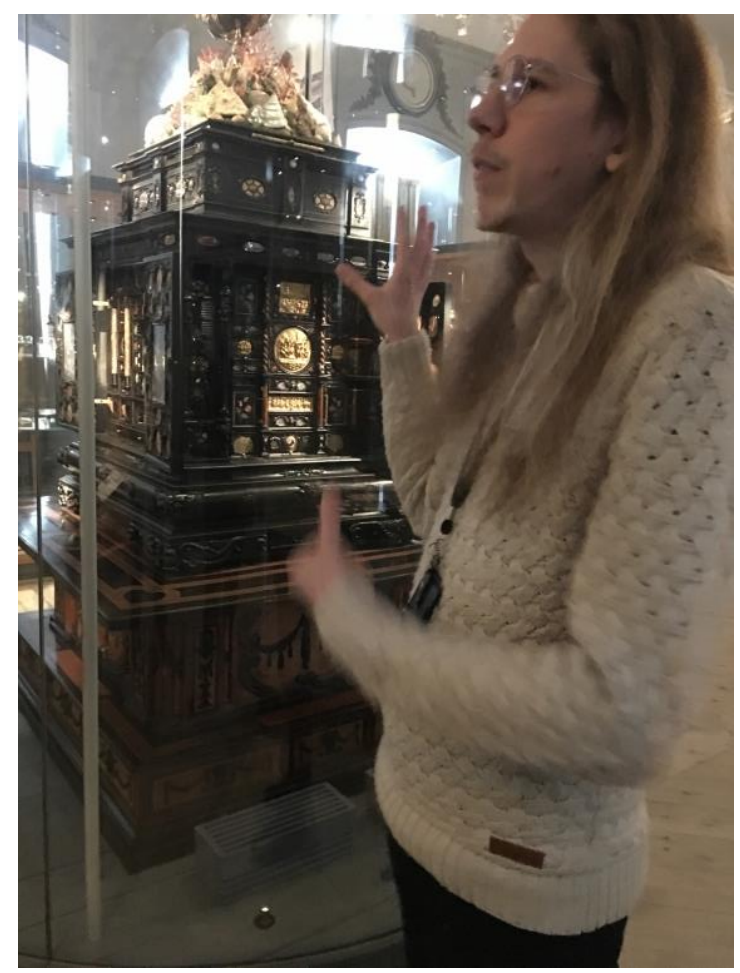


Figure 5. My view as I sit in the corner of the gallery that holds the "digital tour" of the cabinet.

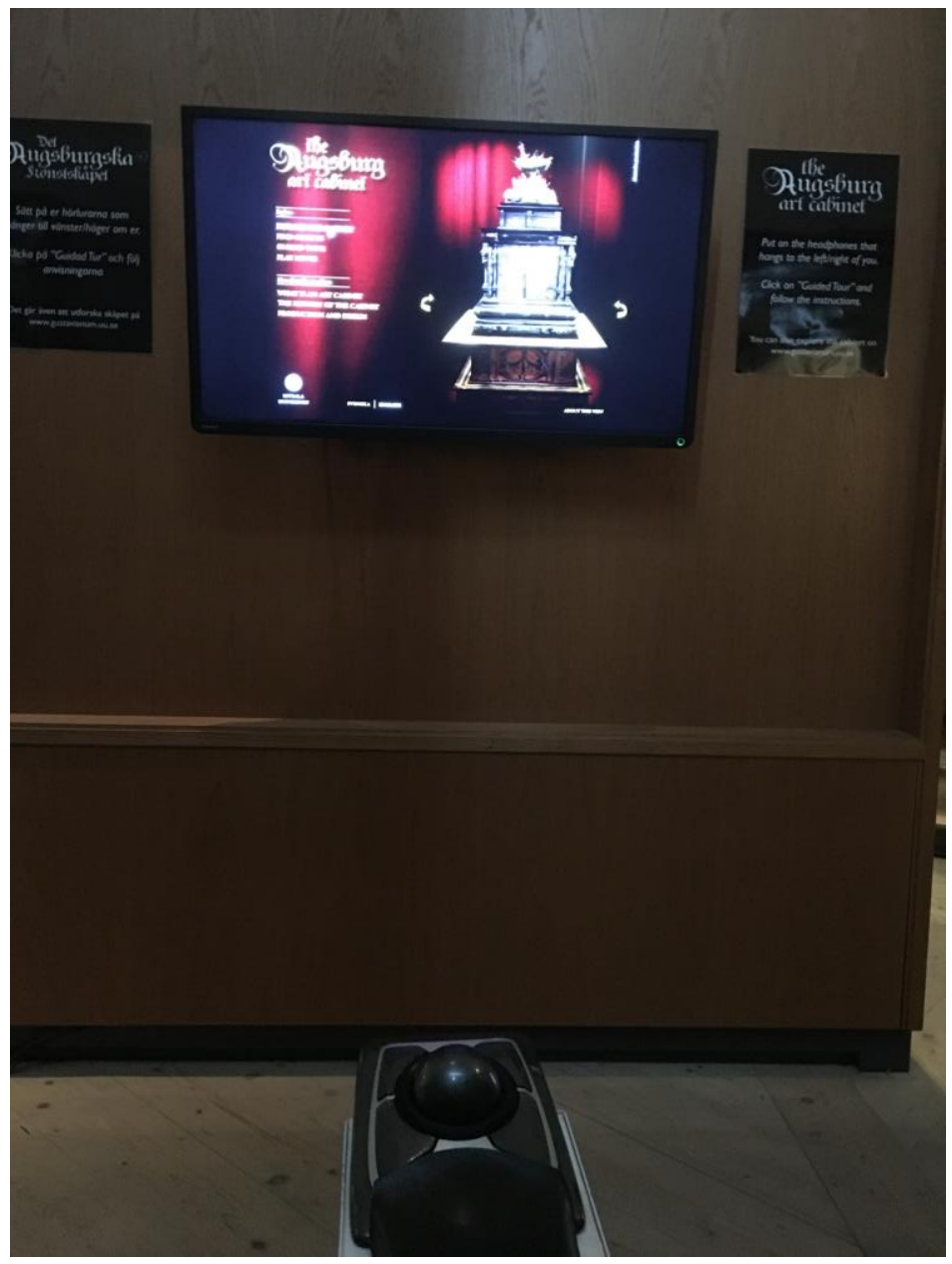

The interactive is available online here, accessible anywhere there is internet, but I wanted to experience all three modes on the same day so I choose to sit in the gallery and use it the way a museum visitor might. In my time there, I saw no one else using the interactive as it was set up in the gallery.

I spent quite a long time trying to figure out how to best use the digital interactive. The introductory screen lists four things to do, in this order: explore the Cabinet, find objects, guided tour, play the movie (see Figure 7). It made sense to me to do these in the order given, but it turned out that the best way to understand how to use it is to start with "guided tour" which is third down in the list. By the time I figured this out, I was frustrated and disapointed several times over. But I went ahead and tried it. If it hadn't been a study, I would have walked away sooner. 
Figure 6 . The view of the cabinet from the digital interactive bench.

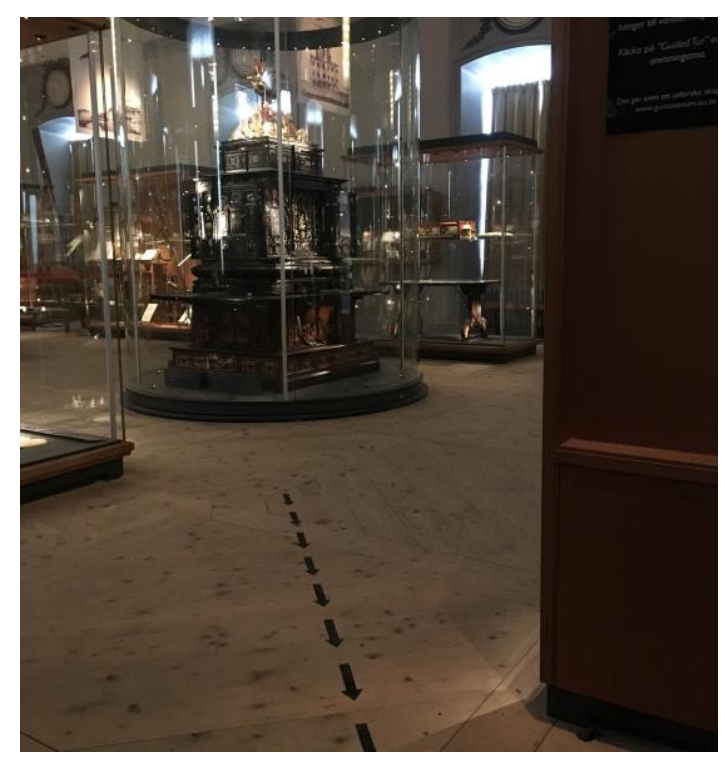

Figure 7. An example of the sequential steps I took to explore the cabinet using the digital tour. The final "discovery" is an empty catalog screen. The orb is circled in red. The blank screen was considered a "disapointment."
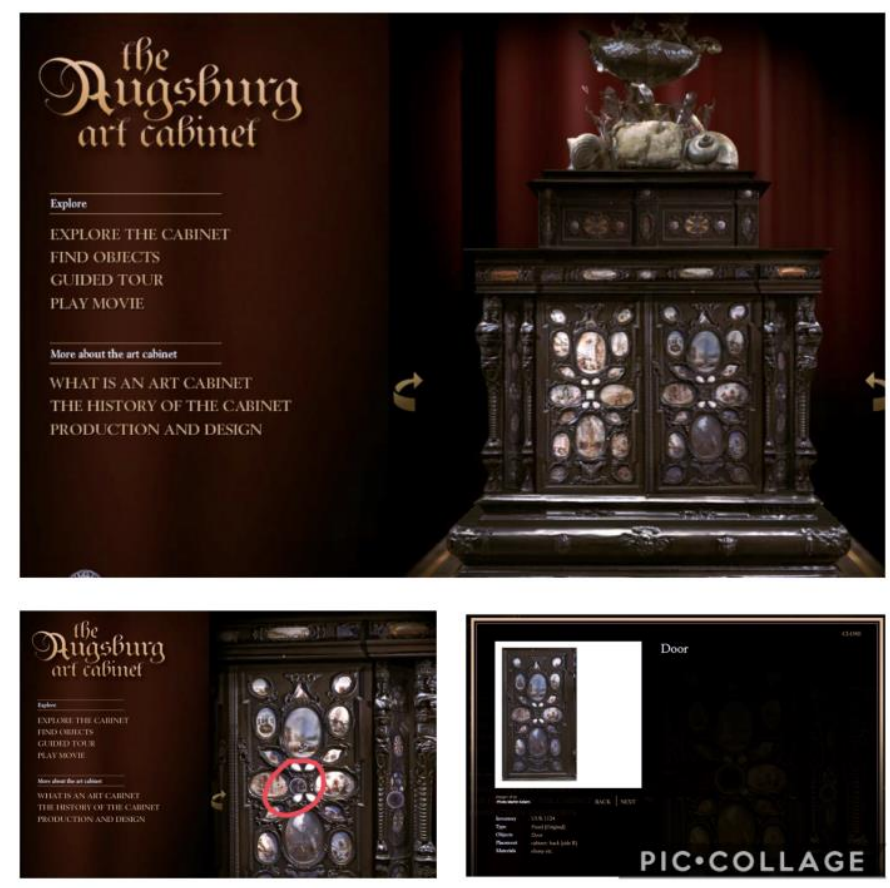
The way it works is that you can "turn" the Cabinet to look at each of the four sides, top, and bottom exploring them more by "going into them," whether by opening a door or a drawer. When you click on the side (there are four sides of the Cabinet) or location (top or bottom), it might open up, presenting a picture of the inner drawers and cabinets. There are orbs hovering over some of these areas and these are where you can go even deeper. The possibilities are exciting, right? However, my frustration continued because the drawers I wanted to investigate did not have orbs. The makers of this interactive only allowed a selection of points to investigate. Sometimes, where there were orbs, the information was minor or even boring (to me). My thoughts at the start of the experience had been that getting to open the Cabinet and explore would be very exciting. It was not. Knowing also that I could do this at home made the experience less interesting and full of frustration and disappointment. Moments considered "discoveries" were comparatively less frequent, and in the context of a fuller meaningful experience, would probably not be as noticeable (see Figure 8).

Figure 8. This example shows one of the more informative screens. This small amount of information was considered a "discovery."
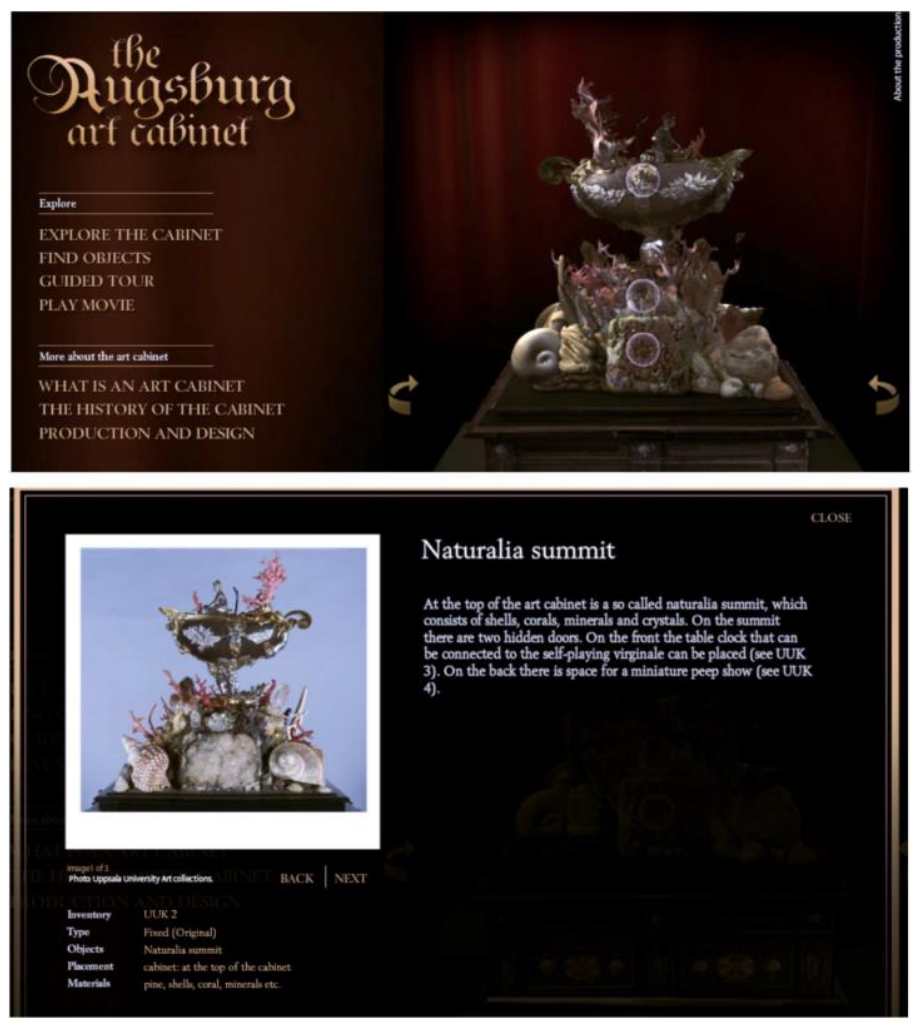
The thematic analysis of the digital tour transcript very clearly revealed the Positive and Negative experiences of the media, with the majority of the encounter spent in the Negative. The theme Positive included subthemes Excited and Hopeful, Cool/neat/fun/surprise, Discovery, interest/inquiry. The Negative theme was consistently and frequently about frustration and disappointment. This involved not understanding what to do with the digital tour, how to use it, and what its purpose was. It also included disappointment, as many activities fell short of my expectations and hopes; there was so much unrealized potential. Because of this binary of experience with the digital tour, and the fact that the majority of it fell in the Negative theme, it was difficult to find any real meaning-making or lived experience beyond these aspects.

\section{The TRT Charting Activity}

Following the experiences of the Cabinet in three modes, I found a local café, got a coffee and a Swedish treat and commenced to "filling out" the four-box chart I had drawn from the original TRT study (see Figure 9 and Table 1 for the short summaries of TRT themes used to do the current reflection). My intention in this part of the data-collection was to use the four ways of experiencing TRT to reflect on my experiences of the three modes of experience-gallery, tour, interactive. I used three different colors to record my reflections into each of the four boxes defined by the TRT study: Self, Relation, Presence, and Surround (see Figure 9).

Figure 9. Four-box TRT chart with reflections coded in color for each of the three types of experiences-purple for gallery visit, blue for docent-led tour, pink for digital tour.

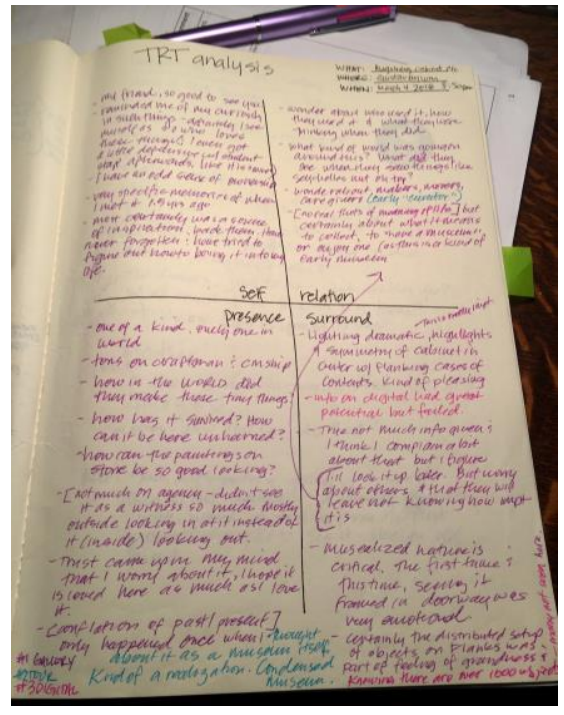


Table 1. Short summaries of the four Ways of Experiencing the Real Thing in the Museum from Latham (2015).

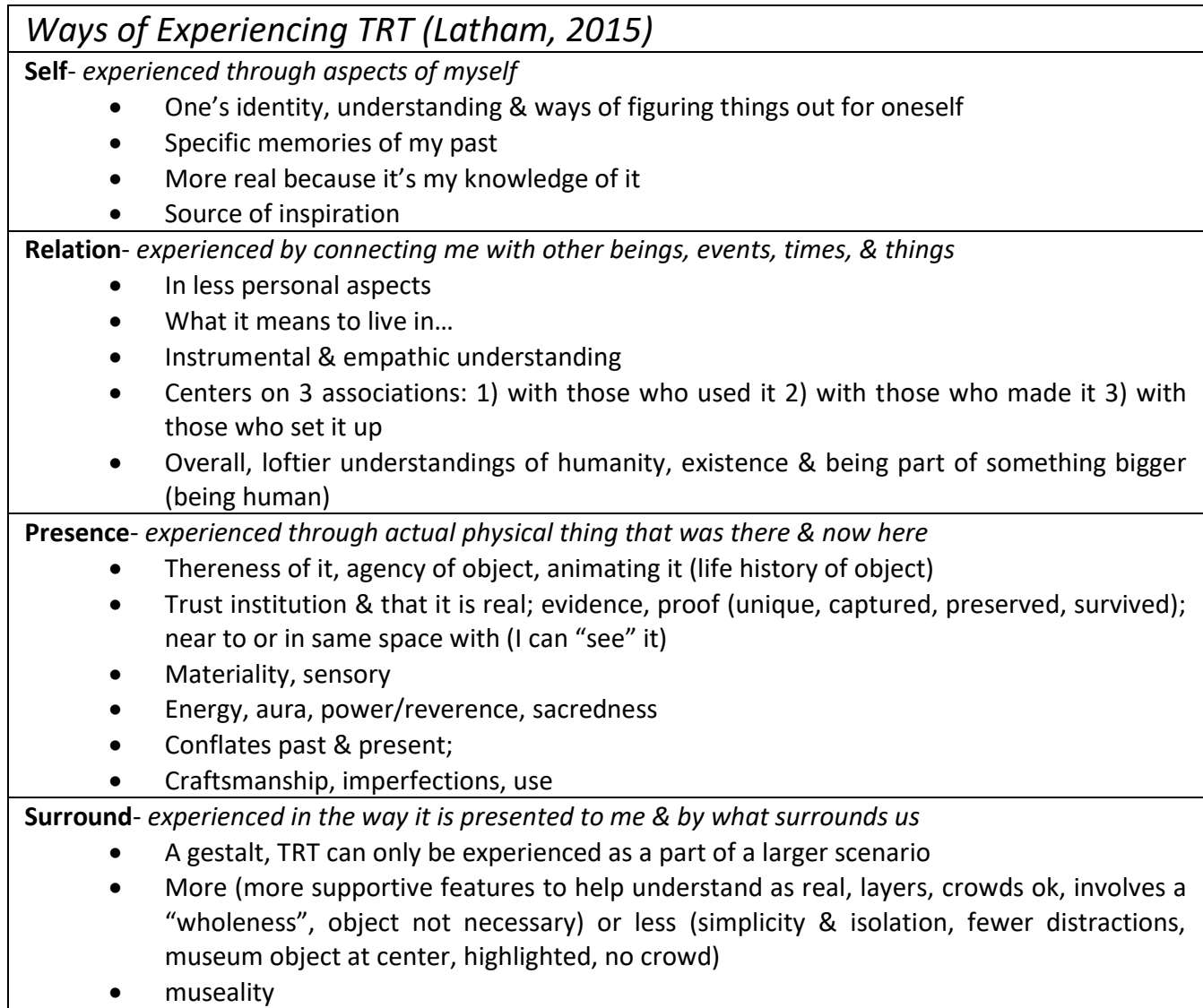

This activity, it turns out, was itself analysis. It did help me to reflect on the experiences in interesting ways, but the only real results were that I had a lot more to say about the live gallery experience, which was not a surprise since that is where I spent the most time and made the longest recording. One small observation is that the one mode of experience in the gallery fell into all four boxes; that the experience itself was multi-dimensional in that it involved four ways of experiencing the real thing.

\section{Thematic Analyses and TRT Ways}

At the completion of the above analyses, I drew up a table of the results (see Table 2) of all components of the study and found that four of the five themes from the live gallery visit transcripts matched up fairly well with the original TRT ways of 
experiencing the real thing. Trying To Figure Things Out was the new category and was, in fact, the highest in quantity.

The difference between these live memo transcriptions and the ones from my earlier study is that mine were in-situ, lived experience and the 2015 study participants described their experiences from memory.

Table 2. Comparative results of all analyses in this study.

\begin{tabular}{|c|c|c|c|}
\hline $\begin{array}{c}\text { Ways of } \\
\text { Experiencing TRT }\end{array}$ & $\begin{array}{c}\text { Gallery Visit } \\
\text { Themes }\end{array}$ & Digital Tour Themes & $\begin{array}{l}\text { From TRT model } \\
\text { charting }\end{array}$ \\
\hline $\begin{array}{l}\text { Self: experienced } \\
\text { through aspects of } \\
\text { myself }\end{array}$ & $\begin{array}{l}\text { Personal } \\
\text { Meaning }\end{array}$ & $\mathrm{N} / \mathrm{A}$ & $\begin{array}{l}\text { Personal attachment } \\
\text { My identity } \\
\text { Personal attachment } \\
\text { Memories } \\
\text { Feelings (inspiration) }\end{array}$ \\
\hline $\begin{array}{l}\text { Relation: experienced } \\
\text { by connecting me with } \\
\text { other beings, events, } \\
\text { times, \& things }\end{array}$ & Wonder & N/A & $\begin{array}{l}\text { People of the past: } \\
\text { - who used it? } \\
\text { - how they used it? } \\
\text { - how they perceived it? } \\
\text { Context of the past: } \\
\text { - contemporary } \\
\text { understandings } \\
\text { - meaning of collecting } \\
\text { People of today: } \\
\text { - concern they will miss it }\end{array}$ \\
\hline $\begin{array}{l}\text { Presence: experienced } \\
\text { through actual } \\
\text { physical thing that was } \\
\text { there \& now here }\end{array}$ & $\begin{array}{l}\text { Appreciating } \\
\text { what I see }\end{array}$ & $\mathrm{N} / \mathrm{A}$ & $\begin{array}{l}\text { - Uniqueness } \\
\text { - Craftsmanship } \\
\text { - Awe at its presence } \\
\text { today } \\
\text { - Information } \\
\text { trustworthy? }\end{array}$ \\
\hline \multirow{3}{*}{$\begin{array}{l}\text { Surround: experience } \\
\text { in the way it is } \\
\text { presented to me \& by } \\
\text { what surrounds us }\end{array}$} & $\begin{array}{l}\text { Surrounding } \\
\text { environment } \\
\text { has an effect }\end{array}$ & $\mathrm{N} / \mathrm{A}$ & $\begin{array}{l}\text { - Presentation elicits } \\
\text { emotional response } \\
\text { - Not enough information }\end{array}$ \\
\hline & $\begin{array}{l}\text { Trying to } \\
\text { figure it out }\end{array}$ & $\begin{array}{l}\text { Positive: } \\
\text { 1. Excited and hopeful } \\
\text { 2. Cool, neat, fun, surprise } \\
\text { 3. Discovery, information found } \\
\text { 4. Interest, inquiry } \\
\text { Negative: Frustration \& } \\
\text { Disappointment }\end{array}$ & \\
\hline & & $\begin{array}{l}\text { Unassigned: } \\
\text { Familiarity }\end{array}$ & \\
\hline
\end{tabular}




\section{Findings, Understandings, and Openings}

After experiencing the cabinet in three ways, I found that the most fertile of the three experiences was the live gallery encounter. I spent the most time with it during this mode, I said the most in the recordings, and wrote the most comments about it in the TRT chart afterwards. Also, it yielded the richest results about experience and meaning-making. The docent-led tour was the least meaningful and my lack of comments and memoing reflects that. This tour was very fact-oriented and did not bring forth anything of interest to me (and in fact, said very little about the many questions I raised during the live gallery encounter). Finally, the digital tour, which promised to let me get deeper into the cabinet, only delivered frustration and disappointment. I found that I had preconceived ideas about what I would be able to do with this interactive and none of these options were available when using it. For example, I was hoping to open all the drawers and look inside, maybe even see what objects would be kept in each drawer. This did not happen. The "tour" was simply a way to get around the museum catalog, giving me metadata and catalog screens that were flat and often empty. I wanted something more vibrant, something to connect me to the owners, the users, the makers (the questions and wonderings that I had in the live gallery visit) but I got clean scrubbed words and rigid short descriptions.

Another lesson from this endeavor is that in-the-moment data collection yields a lot of interesting processual things from my thinking that I otherwise might have ignored or not even noticed. The overwhelming theme for the digital tour was frustration. It was impossible to get past that and onto learning or experiencing or meaning-making. And the additional theme-Trying to Figure it Out-for the live gallery visit reflected this processual activity, something that did not come out at all in my earlier research. I hope to investigate this aspect further.

Regarding the use of TRT ways as a framework, I did not find it useful for deep analysis. But I did discover that the four ways are not necessarily as compartmentalized as I may have been understanding them. In other words, I cannot say, "I am a Presence Person" because the mapping onto the TRT chart showed that all four ways of experiencing-at least for me-were present during the whole experience. Although I have always indicated that the categories were not mutually exclusive, it was interesting nevertheless to see all four ways of experiencing in my one encounter with a single document. This aspect deserves more inquiry. Perhaps more importantly, almost none of these ways of understanding TRT were mapped for the other two modes of experiencing the Cabinet. Very little was charted from the tour or digital interactive. Why is that? What was it about the content of the experience that yielded so little meaningful 
data? What was noticeable was that most of that experience, for me, was with the object itself. It elicited the most reaction, emotion, questions, and pondering.

A possible limitation surfaces in this study: the order in which I encountered each mode. Does order matter? Is there something about this particular order that yielded the results? Would I have written or memoed more in the docent-led tour and digital tour if either had been first? Does the visit to the actual object first help to understand and experience the other two modes? Or did it create expectations of the later modes that were unrealistic? And the opposite situation, if the order were reversed, would the gallery experience be as meaningful and the digital interactive more interesting? This small study revealed such questions and perhaps can contribute over time to a model of how to maximize a document experience by increasingly personal modes of exploration.

On a personal level, I learned, perhaps confirmed, that I get more out of live gallery visits than tours and digital interactives. I knew this about myself but seeing the sheer quantity of the data from the three surprised me.

\section{So What?}

From this experiment, I have become more interested in the notion of capturing lived experience as it happens-in-the-moment. Of course, I know that this is not entirely possible, for as pre-reflective experience happens, it is almost immediately in the past, and therefore reflective experience (van Manen, 1991). But Kari's challenge keeps ringing in my ears: How can we capture more in-the-moment information experiences? This study and Kari's words, have led me to work on yet another study, one that intentionally seeks to capture inner voices, thoughts, emotions, considerations.

\section{References}

Frohmann, B. (2009). Revisiting "what is a document?" Journal of Documentation, 65(2), 291-303.

Gorichanaz, T. (2017). Auto-hermeneutics: A phenomenological approach to information experience. Library \& Information Science Research, 39(1), 17.

Gorichanaz, T., Latham, K.F., \& Wood, E. (2018). Lifeworld as "unit of analysis". Journal of Documentation, 74(4), 880-893.

Josefsson, U. (2014). The Augsburg art cabinet. Uppsala: Uppsala Universitet.

Kari, J. (2007). A review of the spiritual in information studies. Journal of Documentation, 63(6), 935-962. 
Latham, K. F. (2015). What is "the real thing" in the museum? An interpretative phenomenological study. Museum Management and Curatorship, 30(1), 220.

Latham, K. F., Gorichanaz, T., \& Narayan, B. (2018). Encountering the muse: An exploration of the relationship between inspiration and information in the museum context. Journal of Librarianship and Information Science. doi: 10.1177/0961000618769976

Latham, K.F., \& Simmons, J. (2014). Foundations of museum studies: Evolving systems of knowledge. Santa Barbara, CA: Libraries Unlimited.

MacGregor, A. (2007). Curiosity and enlightenment: Collectors and collections from the sixteenth to the nineteenth century. New Haven \& London: Yale University Press.

Smith, J. A., Flowers, P., \& Larkin, M. (2009). Interpretative phenomenological analysis: Theory, method and research. Los Angeles: Sage.

Uppsala Universitet. (n.d.). The anatomical theatre. Retrieved from http://www.gustavianum.uu.se/gustavianum-eng/exhibitions/permanentexhibitions/the-anatomical-theatre

Van Manen, M. (1990). Researching lived experience: human science for an action sensitive pedagogy. Albany: State University of New York Press.

Van Manen, M. (2011). Phenomenology online. Retrieved from http://www.phenomenologyonline.com/

Van Manen, M. (2014). Human science methods: Empirical and reflective activities. In Phenomenology of practice: Meaning-giving methods in phenomenological research and writing (pp. 311-341). Walnut Creek, CA: Left Coast Press. 